\title{
Information content of options trading volume for future volatility: Evidence from the Taiwan options market
}

\author{
Chuang-Chang Chang ${ }^{\mathrm{a}}$, Pei-Fang Hsieh ${ }^{\mathrm{a}}$, Yaw-Huei Wang ${ }^{\mathrm{b} *}$ \\ ${ }^{a}$ Department of Finance, National Central University, No.300, Jhongda Road, Jhongli City, Taoyuan County \\ 32001, Taiwan \\ ${ }^{\mathrm{b}}$ Department of Finance, National Taiwan University, No.1, Section 4, Roosevelt Road, Taipei 10617, Taiwan
}

This Version: July 2009

\begin{abstract}
This study follows the approach of Ni, Pan and Poteshman (2008) - based upon the vega-weighted net demand for volatility - to determine whether volatility information exists within the Taiwan options market. Our empirical results show that foreign institutional investors possess the strongest and most direct volatility information, which is realized by the delta-neutral options/futures trades. In addition, a few individual investors (less than 1\% of individuals' trades) might be informed and realize their volatility information using the strangle strategy. Surprisingly, we find no evidence to support the predictive ability of the volatility demand from straddle trades, despite the widespread acknowledgement that such trades are sensitive to volatility.
\end{abstract}

JEL classification: G14

Keywords: Option volume; Volatility; Emerging markets; Foreign investors

${ }^{*}$ Corresponding author. Tel.: +886 23366 1092; Fax. +886 283695581.

E-mail addresses: ccchang@cc.ncu.edu.tw (C.-C. Chang), 93448004@cc.ncu.edu.tw (P.-F. Hsieh), yhwang@management.ntu.edu.tw (Y.-H. Wang). 


\section{Introduction}

As the data on derivatives trading becomes more readily accessible, a growing body of literature has begun to emerge in which the focus is being placed upon the information content of derivatives trading with regard to the future dynamics of the underlying asset prices. The focus in the majority of these studies has tended to be placed on the predictive potential of option-implied information on the direction, volatility or density of the underlying asset price. ${ }^{1}$

Some studies explore the aggregate option trading volume, as opposed to using option implied information, finding that this approach provides useful information for predicting the dynamics of the underlying asset price. For example, using datasets containing comprehensive transaction records, Pan and Poteshman (2006) and Chang et al. (2009) show that the transactions of different categories of option traders reveal varying degrees of directional information, whilst Ni et al. (2008) find that the trading volume of non-market makers contains volatility information. ${ }^{2}$

To the best of our knowledge, no study has yet utilized the complete transaction records of an options market to investigate which category of option traders (domestic institutional traders, foreign institutional traders or individuals) possess volatility

1 See Canina and Figlewski (1993), Jorion (1995), Fleming (1998), Blair et al. (2001), Poon and Granger (2003), Pong et al. (2004), Jiang and Tian (2005), Doran et al. (2007), Konstantinidi et al. (2008) and Bedendo and Hodges (2009).

2 See also Chan et al. (2002), Chakravarty et al. (2004), Cao et al. (2005) and Chern et al. (2008). 
information. ${ }^{3}$ Our study contributes to the extant literature by filling this gap through the empirical analysis of a unique dataset which includes the complete history of all transactions and orders for options and futures written on the Taiwan Stock Exchange Capitalization Weighted Stock Index (TAIEX). ${ }^{4}$ The motivation for our examination of the Taiwan market comes not only from its institutional background, but also from the investigation of this market in numerous prior studies.

In a matured option market like the US, the index option trading and prices are mainly driven by public information and thus there is rarely information asymmetry among market participants, while it could be existent in the trading of individual stock options. However, foreign investors' capital flows have been found to be highly influential in the emerging financial markets (Froot et al., 2001; Griffin et al., 2004 and Richard, 2005) and are large enough to create a substantial price pressure for the whole market. Meanwhile, the details of foreign investors' trading activities in the emerging markets are usually less transparent or made public with some degree of delay. Therefore, the information asymmetry in these markets could be much more prevalent than that in the matured markets, even for index options, and thus foreign investors' trading

3 Despite investigating all CBOE-listed options, Ni et al. (2008) are only able to identity whether or not a transaction is executed by a market maker.

4 This dataset comprises of the complete records for every transaction and order. In particular, the artificial investor identity number contained within every record reveals the category in which the transaction or order trader belongs. Moreover, if a transaction or order is part of a combination trade including straddle, strangle, money spread, calendar spread and conversion/reversals, it can be clearly identified with the type. 
activities of index options in the emerging markets may include the information for the dynamics of future prices.

Taiwan capital market is one of the major emerging markets ${ }^{5}$ and Barber et al. (2009) and Chang et al. (2009) demonstrate that the Taiwan capital market is largely influenced by inflows from foreign institutional investors, who reportedly earn money in the Taiwan stock market, and possess directional information in the Taiwan option market. ${ }^{6}$ It therefore seems quite natural to ask whether foreign institutional investors in the Taiwan options market also possess such information with regard to volatility.

Our unique dataset facilitates the identification of all kinds of trading strategies. As regards vanilla option transactions, in addition to the aggregate trading volume, we also generate the volume of trades undertaken to open new positions and those undertaken to close existing positions, since this is believed to carry different information content from aggregate volume (Pan and Poteshman, 2006).

In addition to vanilla option trades, combinations of trading strategies, based

5 According to the survey of the World Federation of Exchanges, by 2007, the Taiwan Stock Exchange had become one of the major exchanges in all of the emerging markets, with the exchange being ranked $21^{\text {st }}$ in the world in terms of market capitalization, and $17^{\text {th }}$ in the world in terms of trading volume. Furthermore, during the same year, TAIEX options and futures were respectively ranked $4^{\text {th }}$ and $14^{\text {th }}$ most frequently traded index options on a global scale.

6 Barber et al. (2009) find that only foreign institutional investors earn money in the Taiwan stock market, whilst Chang et al. (2009) find that only foreign institutional investors' trade contain information in the Taiwan options market. Referring to the Taiwan Futures Exchange (TAIFEX) reports, they also find that only market makers and foreign institutional investors earn money in the Taiwan option market. 
upon expectations of volatility, should potentially contain abundant information on future volatility. ${ }^{7}$ We generate the trading volume of those strategies that are generally recognized as volatility trades, such as straddle and strangle, and also follow Chaput and Ederington (2005) to construct an additional volatility-sensitive trade, comprising of a combination of options and futures trades with an almost neutral delta and a non-zero gamma and vega. We also use trading volume for certain other popular combination trading strategies, including money spread and calendar spread, for the purpose of comparison.

Following Ni et al. (2008), we convert eight types of trading volume for market aggregation and for each category of option traders into the vega-weighted demand for volatility, which then represents our information variable. ${ }^{8}$ Our empirical findings, in line with previous studies on directional information, indicate that foreign institutional traders also possess volatility information.

An examination of the trading volume for various categories of traders shows that different categories of traders use different trading strategies to realize their volatility information. Informed individuals tend to trade on their volatility information by using

$7 \quad$ As suggested by Chaput and Ederington (2005), a volatility trading strategy should have a low delta, a high gamma, a high vega, and low transaction costs. Chaput and Ederington (2003) show that the trading volume of combination trades, such as straddle and strangle trades are very sensitive to volatility changes.

8 The details of the construction of this measure are provided in Section 2. 
strangle trades ${ }^{9}$, whilst the strongest and most direct prediction is made by the volatility demand from foreign institutional traders compiled from the delta-neutral options/futures trades, which are believed to be a more appropriate proxy for volatility trades. Surprisingly, we find no evidence to suggest any predictive ability from the volatility demand of straddle trades, despite the widespread acknowledgement of such trades being sensitive to volatility.

The following section presents and develops our empirical methodology, Section 3 describes the data used for our empirical investigation, Section 4 details the empirical results of this study, Section 5 provides a discussion and a check for robustness, and finally Section 6 concludes.

\section{Empirical methodology}

We begin, in this section, by describing the construction of the variable that will represent the information released by the trading volume of various types of trades executed by all traders, and by various categories of traders. We then go on to specify the empirical model used to test the information content of option trades for the prediction of future volatility.

\subsection{Information variables}

9 Less than $1 \%$ of individuals' trades are strangles. Therefore, only a few individuals are informed, in terms of volatility information. 
We adopt the vega-weighted net demand for volatility, as proposed by Ni et al. (2008), to measure the quantity of information released by the trading volume. The volatility demand at time $t$ is defined as:

$$
\begin{aligned}
D_{t}^{\sigma} \equiv \sum_{K} \sum_{T} & \frac{\partial \ln C_{t}^{K, T}}{\partial \sigma_{t}}\left(\text { BuyCall }_{t}^{K, T}-\text { SellCall }_{t}^{K, T}\right) \\
& +\sum_{K} \sum_{T} \frac{\partial \ln P_{t}^{K, T}}{\partial \sigma_{t}}\left(\text { BuyPutl }_{t}^{K, T}-\text { SellPut }_{t}^{K, T}\right)
\end{aligned}
$$

where $C_{t}^{K, T}$ and $P_{t}^{K, T}$ respectively denote the prices of the call and put with strike price $K$ and maturity $T ; \sigma_{t}$ is the volatility of the underlying asset; BuyCall ${ }_{t}^{K, T}$ and SellCall $_{t}^{K, T}$ respectively represent the numbers of bought and sold call contracts with strike price $K$ and maturity $T$, and similarly $B u y P u t_{t}^{K, T}$ and $S e l l P u t_{t}^{K, T}$ respectively represent the numbers of bought and sold put contracts.

If informed investors realize their volatility information on the underlying asset within the option market, we can observe the change in volatility demand caused by the variation in options trading volume. As the vega measures the sensitivity of an option price with regard to volatility, and is positive for both call and put options, the volatility demand will increase (decrease) with long (short) calls or puts.

Since options with different time-to-expiration or strike prices have different vegas, the different positions of trading volume are weighed across time-to-expiration 
and strike prices with their corresponding vegas to construct the volatility demand. ${ }^{10}$ Following Ni et al. (2008), we approximate $\partial \ln C_{t}^{K, T} / \partial \sigma_{t}$ and $\partial \ln P_{t}^{K, T} / \partial \sigma_{t}$ using the Black-Scholes respective call and put vegas, as follows:

$$
\frac{\partial \ln C_{t}^{K, T}}{\partial \sigma_{t}} \approx \frac{1}{C_{t}^{K, T}} \cdot \frac{\partial C_{t}^{K, T}}{\partial \sigma_{t}} \text { and } \frac{\partial \ln P_{t}^{K, T}}{\partial \sigma_{t}} \approx \frac{1}{P_{t}^{K, T}} \cdot \frac{\partial P_{t}^{K, T}}{\partial \sigma_{t}}
$$

In calculating the vegas, we follow Parkinson (1980) to estimate the volatility of the underlying asset at time $t$ using the following formula:

$$
\hat{\sigma}_{t}^{2} \equiv \frac{\left(H_{t}-L_{t}\right)}{4 \ln (2)}
$$

where $H_{t}$ and $L_{t}$ are the highest and lowest prices at time $t$.

We then take the historical 60-trading-day average as the volatility input to mitigate the estimation noise.

\subsection{Model specifications}

If an informed investor does indeed bring private information on future volatility into the options market, then we could expect the net demand for volatility to be positively related to the future volatility of the underlying asset. The empirical model is specified as follows:

$$
R V_{t}=\alpha+\beta \cdot D_{t-j}^{\sigma}+\gamma_{1} \cdot R V_{t-1}+\gamma_{2} \cdot R V_{t-2}+\gamma_{3} \cdot R V_{t-3}+\gamma_{4} \cdot R V_{t-4}+\gamma_{5} \cdot R V_{t-5}
$$

\footnotetext{
10 We exclude those options with a time to expiration of less than five days so as to avoid the impact of the liquidity problem imposed on very short-term contracts.
} 


$$
+\phi \cdot I V_{t-1}+\lambda_{1} \cdot O P V_{t-j}+\lambda_{2} \cdot I N V_{t-j}+\lambda_{3} \cdot A D_{t-j}+\varepsilon_{t}
$$

where $R V_{t}$, which denotes the realized volatility of the underlying asset on day $t$, is defined as the difference of the intraday highest and lowest prices divided by the closing price. ${ }^{11}$

We consider several control variables, each of which may have some influence on the prediction of volatility; $R V_{t-i}$ for $\mathrm{i}=1,2, \ldots$ or 5 is the $i$-day lagged realized volatility used to control for volatility clustering and possible patterns ${ }^{12}$, whilst $I V_{t-1}$ is the average implied volatility of the (nearest) at-the-money call and put options with the shortest maturity (of at least five trading days) on day $t-1$, which is generally found to be the best predictor for future volatility. The remaining variables are related to $D_{t-j}^{\sigma}$, the net demand for volatility at day $t-j . O P V_{t-j}$ refers to the number of options contracts on day $t-j$; and $I N V_{t-j}$ is the logarithmic trading volume of the underlying asset on day $t-j$.

11 Using the same realized volatility measure, the results of Alizadeh et al. (2002) are found to be robust to several alternative definitions of realized volatility.

12 As suggested by Laknishok et al. (2007), investors may be more likely to sell their long position when volatility is high, and in the following days, the volatility decreases due to mean reversion. In order the control for the spurious relation between volatility demand and future volatility, we include the realized volatility levels of past 5 days as the independent variables and expect to see volatility mean reversion. In addition, we classify the volatility demand based on the quartiles of realized volatility averages and find neither a particular open-long volatility demand during the low volatility period nor a noticeable close-sell volatility demand during the high volatility period for any category of traders. We thank the referee for this important issue. 
In addition to trading on volatility information, informed traders may also tend to trade on directional information in the options market (Pan and Poteshman, 2006; Chang et al., 2009). We therefore control for the potential impact of directional information trades on future volatility through the variable $A D_{t-j}$, which is the absolute difference between the sum of the delta-weighted long volume and the sum of the delta-weighted short volume at time $t-j$, with the delta being computed in a similar way to the Black-Scholes vega.

We estimate the regression separately for different values of $j$, from 1 to 5 , in order to investigate whether the net demand for volatility can predict the $j$-day ahead realized volatility. If informed traders do trade on their volatility information in the options market, we would expect the coefficient $\beta$ to be positively significant in some of the $j$-day ahead predictive regressions.

\section{Data}

We obtain the data used in this paper from the Taiwan Futures Exchange (TAIFEX). Our dataset comprises of the complete history of all transaction and order records for TAIEX options and futures covering the period from 21 December 2001 to 24 December 2005. Each transaction or order record includes details on the trader account number, trader category indicator, strategy type, price, quantity, buy-sell indicator, product type, strike price and time-to-expiration. 
We collect the TAIEX spot index closing prices, returns and volume from the Taiwan Economic Journal (TEJ) database covering the period from December 2001 to December 2005. We use the value-weighted average of NT\$ deposits interest rates in domestic banks, compiled by the Central Bank of Taiwan, as a proxy for the risk-free rate.

Following the classifications provided by Chang et al. (2009) and disregarding the transactions of market makers, ${ }^{13}$ we filter the daily options trading volume of non-market makers into four types of trades, open-buy (buying calls or puts to open new positions), open-sell (selling calls or puts to open new positions), close-buy (buying calls or puts to close existing short positions), and close-sell (selling calls or puts to close existing long positions), to calculate the demand for volatility from openand close-option volume.

As the margin requirements for combination trading strategies differ from those of naked-position trades, the TAIFEX identifies and records four types of combination trades, straddle, strangle, money spread and calendar spread. ${ }^{14}$ The straddle and

13 Market makers, who are the liquidity providers, are generally believed to posses no information.

14 The TAIFEX also identifies and records conversion and reversal trades; however, as the volume of such trades is very small, and since foreign institutional traders in particular seldom execute these two strategies, we exclude them from our study. 
strangle trades are commonly regarded as trades which are sensitive to volatility, ${ }^{15}$ whilst the money and calendar spreads are less sensitive to volatility. As suggested by Chaput and Ederington (2005), the options/futures combination with a neutral delta is also a significant source of volatility trades; thus, we also identify this type of combination trade for the calculation of the volatility demand. ${ }^{16}$ We calculate the volatility demand from these combination trades not only for the market aggregation, but also for the three main investor categories.

Table 1a presents the summary statistics of the common variables, $R V, I V$ and $I N V$, whilst Table $1 \mathrm{~b}$ presents those of the option-volume variables, $D^{\sigma}, A D$ and $O P V$, for various trading strategies. Consistent with the general findings within the extant literature, implied volatility $(I V)$ is, on average, close to realized volatility $(R V)$, albeit slightly higher, with the former being more stable over time than the latter. Both $R V$ and $I V$ are positively skewed, and the average logarithm of the daily index trading volume (INV) is 15.08 , with volatility of 0.37 .

$<$ Tables 1a and 1b are inserted about here $>$

\footnotetext{
15 As compared to Ni et al. (2008), who construct the demand for volatility from options volume which may or not have been part of straddle trades, our definition of straddle trades is more accurate.

16 To construct the delta-neutral combinations, we examine the daily open interest for each trader in TAIEX futures and options and pick up the combinations with an approximately zero delta. Assuming traders are delta-neutral at the beginning of each trading day, we only need to calculate the sum of the open interest at the end of the trading day. Note that the delta-neutral combinations must have a non-zero gamma and vega.
} 
The vega-weighted non-market maker net demand for volatility $\left(D^{\sigma}\right)$ from overall trading volume has a mean value of 13,685.92, which indicates that, on average, non-market makers have long-volatility positions. The volatility demand from open volume has a more positive mean than overall volume, whilst it is negative for close volume, which indicates that non-market makers generally open new long-volatility positions whilst selling to close their existing positions.

On average, straddle and strangle trades have a negative net demand for volatility, whilst delta-neutral options/futures trades exhibit strongly positive volatility demand. Conversely, the trading volume from those trades that are less sensitive to volatility, such as money spread and calendar spread, show no obvious positive or negative demand for volatility; the magnitudes of their mean levels are comparatively small. In general, the standard deviations of the volatility demand from all types of trading volume are very large; it is therefore necessary to further dynamically investigate the sources of volatility information.

The mean levels of the absolute values of the delta-weighted sum $(A D)$ are: overall options (2,609.57), open options $(4,171.08)$ and close options $(4,710.98)$, whilst the mean levels of the option volume $(O P V)$ are: overall contracts $(149,664)$, open contracts $(83,543)$ and close contracts $(66,120)$. According to the $A D$ s and $O P V \mathrm{~s}$ of various combination trades, we find that the options/futures combination is the most 
active combination trade, with a daily mean level of options contract trading volume of 42,630. Consistent with the findings of Lakonishok et al. (2007), the mean volumes of the conventional volatility trades such as straddle and strangle are quite small (561 and 2,056 contracts per day, respectively).

Table 2 reports the summary statistics of the option-volume variables for the categories of alternative traders. We find that domestic institutional traders generally take up short positions in volatility demand, since their straddle, strangle and options/futures trades have negative values of net volatility demand. They tend to open new short positions and close them by longing their volatility trades, which indicates that domestic institutional traders are, in general, suppliers of volatility trades.

Conversely, foreign institutional traders are essentially demanders of volatility trades, since their straddle, strangle and options/futures trades display obvious positive demand for volatility. Interestingly, the various trading strategies of individual traders reveal mixed results in the demand for volatility. Their straddle and strangle trades show negative volatility demand, whereas their options/futures trades indicate positive demand for volatility.

$<$ Table 2 is inserted about here $>$

Observing the $O P V \mathrm{~s}$ across different categories of traders, we find that individual traders are the main non-market maker participants in the TAIEX index options market, 
as regards both market aggregation and volatility-sensitive trades, such as straddle, strangle and options/futures trades. By contrast, foreign institutional traders have the smallest number of trades, with an average of just 438 contracts of options/futures trades during each trading day.

We report the correlation coefficients for the main variables used for our empirical analysis in Table 3. The correlation matrix shows a strongly positive correlation between implied volatility and realized volatility. As to the relationships among various categories of option volumes, we find a significantly positive relation between the options/futures and overall (open) volume, while the other option volumes do not show any significant relation.

$<$ Table 3 is inserted about here $>$

\section{Empirical results}

In this section, prior to investigating which traders possess volatility information, we first explore the information content of the volatility demand from alternative vanilla option trades, and then from alternative combination trades on a market-aggregation basis. To attempt to answer our main research question, we further examine the volatility forecasting ability of the volatility demand compiled from the alternative vanilla option trades and various combination trades for the different categories of traders. Finally, we provide some discussion of our empirical results, 
along with a check for robustness.

\subsection{Information content of market aggregate trading volume}

Table 4 reports the estimation results of the prediction regression (Equation 4) for overall volume (Panel A), open volume (Panel B) and close volume (Panel C). If the option trading volume contains information on future volatility, we should observe a significantly positive coefficient of $D^{\sigma}$. Although we essentially focus on one-dayahead prediction, the lagged period for certain independent variables, including $D^{\sigma}$, which ranges from 1 to 5 , captures the potential forecasting power of volatility demand for future realized volatility in the TAIEX.

In terms of overall options volume, we find that the volatility demand contains significant volatility information for one-day-ahead realized volatility, but at only the significance level of 10 per cent. However, when separating the overall net demand for volatility into two groups, open and close volume, although some of the prior studies, such as Pan and Poteshman (2006), suggest that open volume may be more informative than either overall volume or close volume, we find that the influence becomes insignificant for open volume, whilst showing significant impact for close volume only in five-day-ahead realized volatility.

$<$ Table 4 is inserted about here $>$

We add control variables into the prediction regression in order to investigate 
whether the net demand for volatility contains any incremental information beyond the publicly observable volatility information. In line with the widely recognized volatility clustering effect, the coefficients of the first three lagged $R V$ 's are all positively significant at the 1 per cent significance level, while the volatility seems to reverse afterward. ${ }^{17}$ Consistent with the general findings, that implied volatility is the best predictor of future volatility, the coefficients of lagged $I V$ are all positively significant at the 1 per cent significance level. Furthermore, we find that, in general, the volume of both option and index trading $(O P V$ and $I N V)$ has significant impacts with regard to determining future realized volatility.

Unlike the control variables referred to above, the variable representing directional information $(A D)$ implied in overall options volume shows no significant impact on future volatility, whilst the directional information implied from both open and close volume does exhibit some significant impact on future volatility. This finding indicates that the directional information from one particular strategy, an open or close position, is more informative for future volatility. Furthermore, the negative (positive) coefficients for open (close) volume imply that there will be a decrease (increase) in future volatility if traders use open (close) positions to trade on their

17 As hoped, volatility shows mean reversion so that we can control for the concern as to a possible spurious relation between volatility demand and future volatility, which has been detailed in Footnote 12. 
directional information.

Following an alternative approach, we extract the net demand for volatility from various combination trades to further investigate whether, on a market-aggregation basis, the volatility information is informative of future volatility. These combination trades include straddle, strangle, options/futures, money spread and calendar spread trades, of which the first three trading strategies are recognized as being sensitive to volatility, whilst the last two are not. The estimation results of the prediction regression across alternative combination trades are reported in Table $5 .^{18}$

$<$ Table 5 is inserted about here $>$

As expected, the volatility demand derived from the trading volume of money spread and calendar spread trades contains no significant information for the prediction of one-day- to five-day-ahead realized volatility, since these trades are not sensitive to volatility. However, despite straddle, strangle and options/futures usually being regarded as volatility-sensitive trades, the predictive power of the volatility demand implied by the trading volume of these three strategies, on a market-aggregation basis, is not as might be expected. The volatility demand extracted from options/futures trades is found to have no significant impact on future realized volatility, whilst strangle trades have some significant impact only on three-day-ahead realized

18 Since the estimation results of the control variables are generally similar to those shown in Table 4, they are omitted here in order to avoid repetition. 
volatility. However, it is really quite surprising to find that the volatility demand from straddle trades are all insignificant, which may well indicate that this type of trade does not, in fact, have any role to play in volatility forecasting.

Regardless of whether volatility demand is compiled from alternative vanilla trades or various combination trades, the empirical results on a market-aggregation basis do reveal some degree of predictive power, although the evidence may not be sufficiently clear. This finding may indicate that the aggregate options trading volume implies ambiguous volatility information. The reason for this could be that some traders are informed, whilst others are not. As a result, the volatility information released by aggregate volume becomes noisy.

Since our unique dataset facilitates the identification of various categories of traders for every trade, in the following section we go on to further investigate the information content on future volatility from the options trading volume of various categories of traders. Our aim is to attempt to answer the question relating to who possesses volatility information.

\subsection{Information content of trading volume of various categories of traders}

We extract the volatility demand from the trading volume corresponding to the alternative option trades of various categories of traders to run the prediction regression; thus, we compile the volatility demand under the two dimensions of 
categories of traders and trade types. Similar to the process undertaken in the previous section, we first run the tests on the alternative vanilla trades for the volatility demand of various categories of traders, and then for various types of combination trades.

Table 6 reports the estimation results of the prediction regression for the volatility demand from the overall, open and close option volume for various categories of traders. Interestingly, only the trading volume of individual traders shows significant predictive power. The one-day- and two-day-ahead predictions of overall volume are significant respectively at the 10 and 5 per cent significance levels, and the five-day-ahead prediction of close volume is significant at the 5 per cent significance level.

\section{$<$ Table 6 is inserted about here $>$}

In contrast to the many of the prior studies, in which it is suggested that foreign institutional traders are more informed, particularly with regard to directional information, when focusing on various vanilla option trades within the financial market in Taiwan, we can find no evidence of the trading volume of foreign institutional traders having predictive ability over future volatility. Although open volume is viewed as being more informative than overall volume, again we can find no evidence in support of this argument, even when we examine the volume for various categories of traders.

It is an undeniable fact that, on a market-aggregation basis, the trades of 
individuals account for the greatest proportion of all trading volume. This phenomenon could explain why we can find no evidence of predictive ability from the volatility demand of institutional traders. We may, however, be able to find more insights from further exploration of the alternative trading strategies of various categories of traders.

We therefore run a prediction regression on the volatility demand from the trading volume for the alternative combination trades of various categories of traders. As time spread and calendar spread are not traded on the volatility expectation, and the test results with regard to market aggregation also do not support their informativeness in future volatility, we focus here on the three volatility-sensitive combination trades.

Table 7 shows the estimation results of the prediction regression for the volatility demand from the straddle, strangle and options/futures trades of various categories of traders. In general, we find that the foreign institutional and individual investors seem to have forecasting ability for future volatility and use different volatility trades to realize their volatility information. As Panel B shows, the volatility demand compiled from the options/futures trades of foreign institutional traders contains the most significant information on one-day-ahead realized volatility at the 1 per cent significance level. ${ }^{19}$ In Panel C, we find that the volatility demand from the strangle

\footnotetext{
19 It should be noted that the daily average options trading volume from the options/futures combination trades of foreign institutional investors is only 438 contracts. However, they provide the greatest and most direct predictive ability on future realized volatility.
} 
trades of individual traders show significant predictive power for three-day-ahead realized volatility, although only at the 10 per cent significance level.

$<$ Table 7 is inserted about here $>$

As suggested by Chaput and Ederington (2005), using the delta-neutral volatility trading strategy is more precise than using the entire option volume. For individual traders, the volatility demand provides satisfactory predictive power in the strangle volume; it is therefore reasonable to assume that a few individuals (less than $1 \%$ of individuals' trades) are informed, but they are less familiar with options/futures combination trades and will tend to select the standard strangle orders provided by the TAIFEX, which is confirmed by the trading volume shown in Table $2 .^{20}$

Although the volatility demand from the overall options volume of foreign institutional traders shows no significant predictive power, the predictive power arising from options/futures combination trades is fairly satisfactory. Thus, it would seem reasonable to assume that foreign institutional traders are more knowledgeable about volatility-sensitive trades, and will therefore tend to use the most convenient method (options/futures combination) to trade on their volatility information.

\section{Discussion and robustness check}

20 The daily average option trading volume for strangle trades by individuals is 1,983 contracts, which is much larger than the volume for domestic institutional traders, at 74 contracts, and for foreign institutional traders, at 394 contracts. 
From a careful comparison between the empirical results on a market-aggregation basis and those for various categories of traders, unsurprisingly, we find that the results in Table 4 are similar to those in Panel C of Table 6, with transactions by individuals accounting for the highest proportion of all trading volume. Therefore, if we were to simply regroup the overall trading volume into two sub-groups, open and close volume, the findings for market aggregation would be similar to those for individual traders.

By contrast, if we were to regroup the overall trading volume according to at least five different combinations of trading strategies, we find that the results for various categories of traders will differ from those for market aggregation, with the former providing more insights. We can basically identify, from the market-aggregation results shown in Table 5, that the trading volume of strangle carry volatility information but the options/futures trades do not; however, when further exploring the trading volume for various categories of traders, we begin to realize that the information from strangle trades comes from individual traders, whilst the strongest and most direct prediction is made by the volatility demand from foreign institutional traders compiled from the delta-neutral options/futures trades.

$\mathrm{Ni}$ et al. (2008) employ an alternative approach to identifying straddle trades; a measure which is referred to as option volume which could form part of straddle trades. Since we are unable to find any evidence to support the predictive power of straddle 
trades, as a check for robustness, we use the approach proposed by Ni et al. (2008) to identify straddle trades and then reanalyze the results. As the definition in this approach is much looser than ours, the number of trades is therefore much larger; however, we are still unable to find any evidence to suggest the volatility forecasting ability of straddle trades, and this is not dependent on whether the trading volume is based on market aggregation or on various categories of traders.

To further check the existence of volatility information trading, we replace the future realized volatility, the dependent variable in our prediction regression (equation 4), with the price/expensiveness of volatility proxies by the difference of implied and realized volatilities, which should be contemporarily affected by the volatility demand. Overall, the findings do not change and the regression results are available upon request.

\section{Conclusions}

In the emerging markets, the foreign investors' capital flows have a great influence on the price change of equity market. Using a unique dataset which provides comprehensive details on all transactions and orders for options written on the TAIEX, we investigate whether volatility information exists in the Taiwan options market. Based on the vega-weighted net demand for volatility, as proposed by Ni et al. (2008), we find that options trading volume does indeed contain some information on future 
realized volatility.

Our empirical findings indicate that the strongest and most direct predictions are made by the volatility demand arising from the delta-neutral options/futures trades of foreign institutional traders; these are believed to be a more appropriate proxy for volatility trades. Meanwhile, we find that a few individual investors might be informed and tend to trade on their volatility information by using strangle trades. Surprisingly, we find no evidence to suggest any predictive ability from the volatility demand of straddle trades, despite the widespread acknowledgement of such trades being sensitive to volatility.

To the best of our knowledge, no study has yet provided any empirical evidence on the existence of volatility information using comprehensive details on all transactions and orders in an options market. This study therefore contributes to the literature by filling this gap, from various dimensions in particular, including trading strategies and categories of traders. 


\section{References}

Alizadeh, S., Brandt, M.W., Diebold, F.X., 2002. Range-based estimation of stochastic volatility models. Journal of Finance 57, 1047-1091.

Barber, B.M., Lee, Y.-T., Liu, Y.-J., Odean, T., 2009. Just how much do individual investors lose by trading? Review of Financial Studies 22, 609-632.

Bedendo, M., Hodges, S.D., 2009. The dynamics of the volatility skew: A Kalman filter approach. Journal of Banking and Finance 33, 1156-1165.

Blair, B.J., Poon, S.-H., Taylor, S.J., 2001. Forecasting S\&P 100 volatility: The incremental information content of implied volatilities and high-frequency index returns. Journal of Econometrics 105, 5-26.

Canina, L., Figlewski, S., 1993. The information content of implied volatility. Review of Financial Studies 6, 659-681.

Cao, C., Chen, Z., Griffin, J.M., 2005. Information content of option volume prior to takeovers. Journal of Business 78, 1073-1109.

Chakravarty, S., Gulen, H., Mayhew, S., 2004. Informed trading in stock and option markets. Journal of Finance 59, 1235-1257.

Chan, K., Chung, Y.-P., Fong, W.-M., 2002. The informational role of stock and option volume. Review of Financial Studies 15, 1049-1075.

Chang, C.-C., Hsieh, P.-F., Lai, H.-N., 2009. Do informed option investors predict stock returns? Evidence from the Taiwan stock exchange. Journal of Banking and Finance 33, 757-764. 
Chaput, J.S., Ederington, L.H., 2003. Option spread and combination trading. Journal of Derivatives 10, 70-88.

Chaput, J.S., Ederington, L.H., 2005. Volatility trade design. Journal of Futures Markets 25, 243-279.

Chern, K.-Y., Tandon, K., Yu, S., Webb, G., 2008. The information content of stock split announcements: Do options matter? Journal of Banking and Finance 32, 930-946.

Doran, J.S., Peterson, D.R., Tarrant, B.C., 2007. Is there information in the volatility skew? Journal of Futures Markets 27, 921-959.

Fleming, J., 1998. The quality of market volatility forecasts implied by S\&P 100 index option prices. Journal of Empirical Finance 5, 317-345.

Froot, K.A., O’Connell, P.G..J., Seasholes, M.S., 2001. The portfolio flows of international investors. Journal of Financial Economics 59, 151-193.

Griffin, J.M., Nardari, F., Stulz, R.M., 2004. Are daily cross-border equity flows pushed or pulled? Review of Economics and Statistics 86, 641-657.

Jiang, G.J., Tian, Y.S., 2005. The model-free implied volatility and its information content. Review of Financial Studies 18, 1305-1342.

Jorion, P., 1995. Predicting volatility in the foreign exchange market. Journal of Finance 50, 507-528. 
Konstantinidi, E., Skiadopoulos, G.., Tzagkaraki, E., 2008. Can the evolution of implied volatility be forecasted? Evidence from European and US implied volatility indices. Journal of Banking and Finance 32, 2401-2411.

Lakonishok, J., Lee, I., Pearson, N.D., Poteshman, A.M., 2007. Option market activity. Review of Financial Studies 20, 813-857.

Ni, S.X., Pan, J., Poteshman, A.M., 2008. Volatility information trading in the option market. Journal of Finance 63, 1059-1091.

Pan, J., Poteshman, A.M., 2006. The information in option volume for future stock price. Review of Financial Studies 19, 871-908.

Parkinson, M., 1980. The extreme value method for estimating the variance of the rate of return. Journal of Business 53, 61-65.

Pong, S.-H., Shackleton, M.B., Taylor, S.J., Xu, X., 2004. Forecasting sterling/dollar volatility: A comparison of implied volatility and AR(F)IMA models. Journal of Banking and Finance 28, 2541-2563.

Poon, S.-H., Granger, C.W.J., 2003. Forecasting financial market volatility: A review. Journal of Economic Literature 41, 478-539.

Richards, A., 2005. Big fish in small ponds: The trading behavior and price impact of foreign investors in Asian emerging equity markets. Journal of Financial and Quantitative Analysis 40, 1-27. 


\section{Table 1a}

Summary statistics of common variables. This table presents the summary statistics of the common variables, $R V, I V$ and $I N V: R V$, which denotes the realized volatility of the underlying asset, is defined as the difference between the highest and lowest intraday prices divided by the closing price; $I V$ is the average implied volatility of the nearest at-the-money call and put options with the shortest maturity (of at least five trading days); and $I N V$ is the log of the trading volume of the underlying asset. The sample period runs from December 2001 to December 2005.

\begin{tabular}{cccccccc}
\hline Variables & Mean & Std. Dev. & Median & Skewness & Kurtosis & Min & Max \\
\hline$R V$ & $23.87 \%$ & $12.73 \%$ & $20.67 \%$ & 1.36 & 5.46 & $2.32 \%$ & $91.29 \%$ \\
$I V$ & $24.08 \%$ & $7.90 \%$ & $23.57 \%$ & 0.45 & 2.41 & $9.65 \%$ & $55.43 \%$ \\
$I N V$ & 15.08 & 0.37 & 15.05 & 0.38 & 2.21 & 14.12 & 16.26 \\
\hline
\end{tabular}




\section{Table 1b}

Summary statistics of different trade variables. This table presents the summary statistics of the option-volume variables, $D^{\sigma}, A D$ and $O P V$ for various trading strategies. $D^{\sigma}$ is the net demand for volatility; $A D$ is the absolute difference between the sum of the delta-weighted long volume and the delta-weighted short volume with the delta computed by similar steps to the Black-Scholes vega; $O P V$ is the number of options contracts. The sample period runs from December 2001 to December 2005.

\begin{tabular}{|c|c|c|c|c|c|c|c|c|c|}
\hline \multirow[t]{2}{*}{ Trade Types } & $D^{\sigma}$ & \multicolumn{7}{|c|}{ Variables } & $O P V$ \\
\hline & Mean & Std. Dev. & Median & Mean & Std. Dev. & Median & Mean & Std. Dev. & Median \\
\hline Overall & $13,685.92$ & $54,044.66$ & $4,035.89$ & $2,609.57$ & 3,266.39 & 1,359.37 & 149,664 & 131,593 & 137,758 \\
\hline Open & $69,541.34$ & $89,046.97$ & $41,290.77$ & $4,171.08$ & $5,740.07$ & 2,333.96 & 83,543 & 69,992 & 80,686 \\
\hline Close & $-55,855.42$ & $82,323.76$ & $-25,754.93$ & $4,710.98$ & $7,235.22$ & $1,977.57$ & 66,120 & 64,961 & 53,137 \\
\hline Straddle & -487.93 & 1042.88 & -155.05 & 51.64 & 108.41 & 13.94 & 561 & 717 & 309 \\
\hline Strangle & $-1,897.33$ & $3,296.14$ & -818.51 & 92.98 & 211.93 & 25.57 & 2,056 & 2,019 & 1,644 \\
\hline Could be straddle & $-5,395.45$ & $20,556.70$ & -799.54 & $1,348.95$ & $2,148.54$ & 556.86 & 29,030 & 32,600 & 19,424 \\
\hline Options/Futures & $6,682.30$ & $11,318.83$ & $3,981.64$ & 392.02 & 376.68 & 271.83 & 42,630 & 33,715 & 41,269 \\
\hline Money spread & -6.92 & 2,913.77 & 22.44 & 232.09 & 380.39 & 67.87 & 1,921 & 2,277 & 1,221 \\
\hline Calendar spread & 258.16 & $1,667.15$ & 13.95 & 55.47 & 290.08 & 2.46 & 109 & 400 & 13 \\
\hline
\end{tabular}




\section{Table 2}

Summary statistics of option-volume variables for categories of alternative traders. This table presents the summary statistics of the option-volume variables, $D^{\sigma}$, $A D$ and $O P V$ across various trading strategies for alternative categories of traders, domestic institutional investors, foreign institutional investors, and individual investors. $D^{\sigma}$ is the net demand for volatility. $A D$ is the absolute difference between the sum of the delta-weighted long volume and the sum of the delta-weighted short volume with the delta computed by the similar steps for the Black-Scholes vega. $O P V$ is the number of option contracts. The sample period is from December 2001 through December 2005.

\begin{tabular}{|c|c|c|c|c|c|c|c|c|c|}
\hline \multirow[t]{2}{*}{ Trade Types } & & \multicolumn{8}{|c|}{ Variables } \\
\hline & Mean & Std. Dev & Median & Mean & Std & Median & Mean & Std & Median \\
\hline \multicolumn{10}{|c|}{ Panel A: Domestic Institutional Traders } \\
\hline Overall & $-5,591.68$ & $16,968.86$ & $-1,066.25$ & 652.46 & $1,055.31$ & 231.97 & 15,132 & 14,766 & 12,059 \\
\hline Open & $-11,448.28$ & $20,913.76$ & $-4,318.17$ & 524.77 & 794.56 & 188.37 & 8,276 & 8,085 & 6,440 \\
\hline Close & $5,868.43$ & $11,249.87$ & $1,629.29$ & 563.61 & $1,070.79$ & 173.76 & 6,869 & 7,278 & 4,796 \\
\hline Straddle & -27.86 & 118.67 & -5.67 & 4.10 & 13.10 & 0.79 & 23 & 52 & 6 \\
\hline Strangle & -94.76 & 323.04 & -19.62 & 3.03 & 9.51 & 0.67 & 74 & 142 & 26 \\
\hline Options/Futures & -309.74 & $1,117.90$ & -40.12 & 11.55 & 26.93 & 6.21 & 1,520 & 1,654 & 1,042 \\
\hline Money spread & -154.78 & 873.68 & -0.01 & 43.89 & 119.96 & 8.54 & 225 & 411 & 77 \\
\hline Calendar spread & 60.55 & 582.63 & 1.64 & 12.08 & 31.16 & 1.10 & 33 & 83 & 4 \\
\hline
\end{tabular}




\section{Table 2 (continuted)}

\begin{tabular}{|c|c|c|c|c|c|c|c|c|c|}
\hline \multirow[t]{2}{*}{ Trade Types } & \multicolumn{8}{|c|}{ Variables } & $O P V$ \\
\hline & Mean & Std. Dev & Median & Mean & Std & Median & Mean & Std & Median \\
\hline \multicolumn{10}{|c|}{ Panel B: Foreign Institutional Traders } \\
\hline Overall & $5,927.36$ & $20,767.08$ & 736.97 & $1,013.38$ & $1,854.99$ & 456.24 & 9,557 & 10,200 & 6,603 \\
\hline Open & $6,762.29$ & $19,886.52$ & $1,005.82$ & 641.46 & $1,195.31$ & 292.18 & 6,626 & 6,928 & 4,467 \\
\hline Close & -880.73 & $10,216.49$ & -0.33 & 908.28 & $2,153.13$ & 296.03 & 3,698 & 4,967 & 1,982 \\
\hline Straddle & 560.34 & $1,871.83$ & 27.11 & 12.26 & 16.55 & 5.07 & 298 & 449 & 103 \\
\hline Strangle & $1,263.96$ & $2,202.16$ & 324.21 & 15.37 & 27.94 & 2.79 & 394 & 638 & 117 \\
\hline Options/Futures & 517.51 & 3,483.37 & 9.15 & 4.09 & 17.24 & 0.20 & 438 & 878 & 100 \\
\hline Money spread & 546.09 & 898.53 & 115.77 & 163.14 & 284.39 & 18.16 & 301 & 491 & 35 \\
\hline Calendar spread & 2,964.94 & $4,641.08$ & 572.62 & 616.88 & $1,015.18$ & 61.48 & 727 & 1,189 & 81 \\
\hline \multicolumn{10}{|c|}{ Panel C: Individual Traders } \\
\hline Overall & $14,545.28$ & $60,257.72$ & $4,219.04$ & $2,991.42$ & $3,627.45$ & $1,662.39$ & 126,901 & 111,350 & 117,728 \\
\hline Open & $75,679.31$ & $94,089.96$ & $46,865.82$ & $4,442.36$ & $5,791.39$ & $2,622.76$ & 70,064 & 58,294 & 67,470 \\
\hline Close & $-61,134.03$ & $87,892.94$ & $-28,114.01$ & 4,798.08 & 7,326.11 & $1,981.68$ & 56,837 & 55,853 & 47,220 \\
\hline Straddle & -485.27 & $1,001.38$ & -150.17 & 50.95 & 108.18 & 13.13 & 545 & 700 & 303 \\
\hline Strangle & $-1,885.64$ & $3,189.08$ & -798.05 & 91.73 & 207.82 & 25.85 & 1,983 & 1,930 & 1,568 \\
\hline Options/Futures & $6,950.29$ & $11,267.13$ & $4,154.88$ & 388.41 & 372.91 & 266.37 & 41,078 & 32,429 & 39,911 \\
\hline Money spread & 102.82 & $2,855.05$ & 38.40 & 217.31 & 350.54 & 71.40 & 1,750 & 2,155 & 1,045 \\
\hline Calendar spread & 234.03 & 1421.44 & 13.88 & 51.18 & 273.61 & 2.32 & 99 & 371 & 11 \\
\hline
\end{tabular}




\section{Table 3}

Correlation Coefficients. This table presents the correlation coefficients between all variables used for our empirical analysis, including realized volatility (RV), 3 control variables (IV, OPV, and INV) and 8 types of volatility demand (overall, open, close, straddle, strangle, options/futures, money spread and calendar spread). The definitions of these variables are detailed in Section 2. The sample period is from December 2001 through December 2005.

\begin{tabular}{|c|c|c|c|c|c|c|c|c|c|c|c|c|}
\hline & $\mathrm{RV}$ & IV & Overall & Open & Close & Straddle & Strangle & Options/Futures & $\begin{array}{l}\text { Money } \\
\text { spread }\end{array}$ & $\begin{array}{c}\text { Calendar } \\
\text { spread }\end{array}$ & $O P V$ & $I N V$ \\
\hline IV & 0.56 & & & & & & & & & & & \\
\hline Overall & -0.03 & -0.15 & & & & & & & & & & \\
\hline Open & -0.30 & -0.55 & 0.42 & & & & & & & & & \\
\hline Close & 0.30 & 0.49 & 0.19 & -0.80 & & & & & & & & \\
\hline Straddle & 0.17 & 0.35 & -0.01 & -0.27 & 0.28 & & & & & & & \\
\hline Strangle & 0.27 & 0.40 & -0.08 & -0.20 & 0.15 & 0.41 & & & & & & \\
\hline Options/Futures & -0.05 & -0.25 & 0.40 & 0.42 & -0.18 & -0.12 & -0.18 & & & & & \\
\hline Money spread & 0.07 & 0.02 & 0.23 & 0.05 & 0.09 & 0.03 & -0.001 & 0.17 & & & & \\
\hline Calendar spread & -0.09 & -0.11 & -0.13 & 0.08 & -0.19 & -0.12 & -0.07 & 0.04 & -0.08 & & & \\
\hline$O P V$ & -0.28 & -0.55 & 0.14 & 0.72 & -0.68 & -0.38 & -0.31 & 0.37 & 0.01 & 0.14 & & \\
\hline$I N V$ & 0.16 & -0.01 & -0.04 & 0.003 & -0.03 & -0.01 & 0.07 & -0.002 & 0.07 & -0.04 & 0.60 & \\
\hline$A D$ & -0.15 & -0.40 & 0.09 & 0.47 & -0.44 & -0.19 & -0.17 & 0.24 & 0.07 & 0.03 & 0.08 & 0.12 \\
\hline
\end{tabular}




\section{Table 4}

Volatility prediction by the options volume of alternative vanilla trades. This table reports the estimation results of the prediction regression (Equation 4) on market aggregation and alternative vanilla trading strategies (open or close positions). The dependent variable of the regressions is the realized volatility of the TAIEX index on trading day $t$. Of the independent variables, we examine the option-volume variables $\left(D^{\sigma}, O P V\right.$ and $\left.A D\right)$ with lagged periods from 1 to 5 . The sample period runs from December 2001 to December 2005. * indicates significance at below the $10 \%$ level; ** indicates significance at below the 5\% level; and *** indicates significance at below the $1 \%$ level.

\begin{tabular}{|c|c|c|c|c|c|c|c|c|c|c|}
\hline \multirow{3}{*}{ Variables } & \multicolumn{10}{|c|}{$j$-value } \\
\hline & \multicolumn{2}{|c|}{1} & \multicolumn{2}{|c|}{2} & \multicolumn{2}{|c|}{3} & \multicolumn{2}{|c|}{4} & \multicolumn{2}{|c|}{5} \\
\hline & Coeff. & t-stat. & Coeff. & t-stat. & Coeff. & t-stat. & Coeff. & t-stat. & Coeff. & t-stat. \\
\hline \multicolumn{11}{|c|}{ Panel A: Overall Volume } \\
\hline Intercept & 788.3159 & 0.58 & -969.6041 & -0.71 & -2354.6760 & $-1.72 *$ & -2730.6160 & $-2.01 * *$ & -1155.3273 & -0.85 \\
\hline$D_{t-j}^{\sigma}$ & 0.0016 & $1.89 *$ & 0.0006 & 0.80 & 0.00001 & 0.02 & -0.0001 & -0.13 & 0.0013 & 1.52 \\
\hline$R V_{t-1}$ & 0.1226 & $3.74 * * *$ & 0.0906 & $2.78 * * *$ & 0.0975 & $3.02 * * *$ & 0.0937 & $2.92 * * *$ & 0.0953 & $2.94 * * *$ \\
\hline$R V_{t-2}$ & 0.1038 & $3.26 * * *$ & 0.1235 & $3.78 * * *$ & 0.1019 & $3.15^{* * *}$ & 0.0985 & $3.09 * * *$ & 0.1003 & $3.14^{* * *}$ \\
\hline$R V_{t-3}$ & 0.0996 & $3.10 * * *$ & 0.1037 & $3.21 * * *$ & 0.1154 & $3.52 * * *$ & 0.1001 & $3.10 * * *$ & 0.1059 & $3.30 * * *$ \\
\hline$R V_{t-4}$ & 0.0421 & 1.31 & 0.043 & 1.33 & 0.0449 & 1.38 & 0.0564 & $1.73^{* *}$ & 0.0318 & 0.98 \\
\hline$R V_{t-5}$ & -0.0144 & -0.45 & -0.0139 & -0.43 & -0.0115 & -0.36 & -0.0203 & -0.63 & 0.0064 & 0.20 \\
\hline$I V_{t-1}$ & 0.4170 & $6.29 * * *$ & 0.4517 & $6.76 * * *$ & 0.4558 & $6.80 * * *$ & 0.4336 & $6.49 * * *$ & 0.4515 & $6.74 * * *$ \\
\hline$O P V_{t-j}$ & -0.0016 & $-5.20 * * *$ & -0.0012 & $-3.79 * * *$ & -0.0011 & $-3.39 * * *$ & -0.0014 & $-4.51 * * *$ & -0.0013 & $-4.21 * * *$ \\
\hline$I N V_{t-\mathrm{j}}$ & -1.4110 & -0.02 & 106.8710 & 1.17 & 197.0415 & $2.17^{* *}$ & $232.0404 \mathrm{v}$ & $2.57 * *$ & 120.8415 & 1.33 \\
\hline$A D_{t-j}$ & -0.0011 & -0.10 & -0.0006 & -0.06 & 0.0061 & 0.55 & 0.0002 & 0.02 & -0.0057 & -0.51 \\
\hline $\operatorname{Adj}-R^{2}$ & \multicolumn{2}{|c|}{0.3525} & \multicolumn{2}{|c|}{0.3388} & \multicolumn{2}{|c|}{0.3379} & \multicolumn{2}{|c|}{0.3415} & \multicolumn{2}{|c|}{0.3386} \\
\hline
\end{tabular}




\section{Table 4 (continued)}

\begin{tabular}{|c|c|c|c|c|c|c|c|c|c|c|}
\hline \multirow{3}{*}{ Variables } & \multicolumn{10}{|c|}{$j$-value } \\
\hline & \multicolumn{2}{|c|}{1} & \multicolumn{2}{|c|}{2} & \multicolumn{2}{|c|}{3} & \multicolumn{2}{|c|}{4} & \multicolumn{2}{|c|}{5} \\
\hline & Coeff. & t-stat. & Coeff. & t-stat. & Coeff. & t-stat. & Coeff. & t-stat. & Coeff. & t-stat. \\
\hline \multicolumn{11}{|c|}{ Panel B: Open Volume } \\
\hline Intercept & 435.1908 & 0.31 & -1401.4858 & -1.00 & -2762.7796 & $-1.98 * *$ & -2735.8569 & $-1.97 * *$ & -842.2051 & -0.60 \\
\hline$D_{t-j}^{\sigma}$ & 0.0005 & 0.95 & 0.0001 & 0.10 & 0.0002 & 0.38 & -0.00003 & -0.05 & -0.0001 & -0.16 \\
\hline$R V_{t-1}$ & 0.1144 & $3.46 * * *$ & 0.0855 & $2.64 * * *$ & 0.0897 & $2.77 * * *$ & 0.0905 & $2.81 * * *$ & 0.0939 & 2.89 \\
\hline$R V_{t-2}$ & 0.1008 & $3.17 * * *$ & 0.1127 & $3.44^{* * *}$ & 0.0969 & $3.01 * * *$ & 0.0944 & $2.95 * * *$ & 0.0991 & 3.09 \\
\hline$R V_{t-3}$ & 0.1001 & $3.13^{* * *}$ & 0.0995 & $3.11^{* * *}$ & 0.1068 & $3.24 * * *$ & 0.0986 & $3.06 * * *$ & 0.1055 & 3.27 \\
\hline$R V_{t-4}$ & 0.0401 & 1.25 & 0.0436 & 1.35 & 0.0412 & 1.28 & 0.0534 & 1.62 & 0.0358 & 1.10 \\
\hline$R V_{t-5}$ & -0.0154 & -0.49 & -0.0153 & -0.48 & -0.0121 & -0.38 & -0.0191 & -0.06 & 0.0096 & 0.30 \\
\hline$I V_{t-1}$ & 0.4021 & $5.89 * * *$ & 0.4298 & $6.33 * * *$ & 0.4495 & $6.61 * * *$ & 0.4242 & $6.26 * * *$ & 0.4226 & $6.22 * * *$ \\
\hline$O P V_{t-j}$ & -0.0029 & $-3.81 * * *$ & -0.0020 & $-2.61 * * *$ & -0.0020 & $-2.61 * * *$ & -0.0027 & $-3.59 * * *$ & -0.0025 & $-3.34 * * *$ \\
\hline$I N V_{t-\mathrm{j}}$ & 29.1697 & 0.31 & 145.6355 & 1.57 & 231.9341 & $2.49 * *$ & 237.2837 & $2.56 * *$ & 106.1915 & 1.14 \\
\hline$A D_{t-j}$ & -0.0167 & $-2.35 * *$ & -0.0164 & $-2.30 * *$ & -0.0141 & $-1.97 * *$ & -0.0027 & -0.38 & 0.0017 & 0.25 \\
\hline $\operatorname{Adj}-R^{2}$ & \multicolumn{2}{|c|}{0.3524} & \multicolumn{2}{|c|}{0.3447} & \multicolumn{2}{|c|}{0.3421} & \multicolumn{2}{|c|}{0.3428} & \multicolumn{2}{|c|}{0.3382} \\
\hline
\end{tabular}




\section{Table 4 (continued)}

\begin{tabular}{|c|c|c|c|c|c|c|c|c|c|c|}
\hline \multirow{3}{*}{ Variables } & \multicolumn{10}{|c|}{$j$-value } \\
\hline & \multicolumn{2}{|c|}{1} & \multicolumn{2}{|c|}{2} & \multicolumn{2}{|c|}{3} & \multicolumn{2}{|c|}{4} & \multicolumn{2}{|c|}{5} \\
\hline & Coeff. & t-stat. & Coeff. & t-stat. & Coeff. & t-stat. & Coeff. & t-stat. & Coeff. & t-stat. \\
\hline \multicolumn{11}{|c|}{ Panel C: Close Volume } \\
\hline Intercept & 662.9488 & 0.47 & -1179.9580 & -0.84 & -2707.4876 & $-1.93 *$ & -2738.5988 & $-1.97 * *$ & -686.9780 & -0.49 \\
\hline$D_{t-j}^{\sigma}$ & 0.0010 & 1.56 & 0.0011 & 1.64 & 0.0004 & 0.66 & 0.0004 & 0.74 & 0.0015 & $2.43^{* *}$ \\
\hline$R V_{t-1}$ & 0.1139 & $3.42 * * *$ & 0.0888 & $2.73 * * *$ & 0.0958 & $2.96 * * *$ & 0.0964 & $2.99 * * *$ & 0.0979 & $3.02 * * *$ \\
\hline$R V_{t-2}$ & 0.1046 & $3.28 * * *$ & 0.1095 & $3.31 * * *$ & 0.1013 & $3.13^{* * *}$ & 0.1014 & $3.17^{* * *}$ & 0.1022 & $3.20 * * *$ \\
\hline$R V_{t-3}$ & 0.1049 & $3.27 * * *$ & 0.1074 & $3.34 * * *$ & 0.1044 & $3.14 * * *$ & 0.1017 & $3.15^{* * *}$ & 0.1071 & $3.33 * * *$ \\
\hline$R V_{t-4}$ & 0.0462 & 1.43 & 0.0522 & 1.61 & 0.0475 & 1.47 & 0.0543 & 1.64 & 0.0352 & 1.08 \\
\hline$R V_{t-5}$ & -0.0064 & -0.20 & 0.0322 & -0.18 & -0.0048 & -0.15 & -0.0183 & -0.57 & 0.0077 & 0.24 \\
\hline$I V_{t-1}$ & 0.4012 & $5.97 * * *$ & 0.0669 & $6.74^{* * *}$ & 0.4738 & $7.09 * * *$ & 0.4510 & $6.76 * * *$ & 0.4360 & $6.51 * * *$ \\
\hline$O P V_{t-j}$ & -0.0017 & $-2.33^{* *}$ & 0.0007 & -0.95 & -0.0011 & -1.42 & -0.0022 & $-3.08 * * *$ & -0.0013 & $-1.84 *$ \\
\hline$I N V_{t-\mathrm{j}}$ & 5.8460 & 0.06 & 92.9874 & 1.26 & 215.4888 & $2.32 * *$ & 225.5155 & $2.43 * *$ & 88.7308 & 0.95 \\
\hline$A D_{t-j}$ & 0.0079 & 1.36 & 0.0073 & 1.25 & 0.0086 & 1.45 & -0.0009 & -0.17 & -0.0057 & -0.96 \\
\hline $\operatorname{Adj}-R^{2}$ & \multicolumn{2}{|c|}{0.3515} & \multicolumn{2}{|c|}{0.3405} & \multicolumn{2}{|c|}{0.3381} & \multicolumn{2}{|c|}{0.3390} & \multicolumn{2}{|c|}{0.3381} \\
\hline
\end{tabular}




\section{Table 5}

Volatility prediction by option volume of alternative combination trades. This table reports the estimation results of the prediction regression (Equation 4) on alternative combination trades. The dependent variable of the regressions is the realized volatility of the TAIEX index on trading day $t$. Of the independent variables, we examine the option-volume variables $\left(D^{\sigma}, O P V\right.$ and $\left.A D\right)$ with lagged periods from 1 to 5 . In order to save space, we do not report the estimates of all of the control variables. The sample period runs from December 2001 to December 2005. * indicates significance at below the 10\% level; ** indicates significance at below the 5\% level; and *** indicates significance at below the $1 \%$ level.

\begin{tabular}{|c|c|c|c|c|c|c|c|c|c|c|}
\hline \multirow{3}{*}{ Variables } & \multicolumn{10}{|c|}{$j$-value } \\
\hline & \multicolumn{2}{|c|}{1} & \multicolumn{2}{|c|}{2} & \multicolumn{2}{|c|}{3} & \multicolumn{2}{|c|}{4} & \multicolumn{2}{|c|}{5} \\
\hline & Coeff. & t-stat. & Coeff. & t-stat. & Coeff. & t-stat. & Coeff. & t-stat. & Coeff. & t-stat. \\
\hline \multicolumn{11}{|l|}{ Straddle } \\
\hline Intercept & 183.52 & 0.13 & -1206.76 & -0.83 & -2438.27 & -1.69 & -2446.61 & -1.73 & -356.60 & -0.25 \\
\hline$D_{t-j}^{\sigma}$ & 0.03 & 0.84 & 0.03 & 0.96 & 0.04 & 1.13 & 0.02 & 0.52 & 0.02 & 0.74 \\
\hline $\operatorname{Adj}-R^{2}$ & \multicolumn{2}{|c|}{0.3095} & \multicolumn{2}{|c|}{0.3125} & \multicolumn{2}{|c|}{0.3175} & \multicolumn{2}{|c|}{0.3223} & \multicolumn{2}{|c|}{0.3066} \\
\hline \multicolumn{11}{|l|}{ Strangle } \\
\hline Intercept & 986.14 & 0.70 & -2088.07 & -1.46 & -3145.86 & $-2.23 * *$ & -3032.81 & $-2.15 * *$ & -812.02 & -0.57 \\
\hline$D_{t-j}^{\sigma}$ & -0.002 & -0.19 & 0.01 & 0.73 & 0.03 & $2.08 * *$ & -0.01 & -0.60 & -0.002 & -0.22 \\
\hline $\operatorname{Adj}-R^{2}$ & \multicolumn{2}{|c|}{0.3192} & \multicolumn{2}{|c|}{0.3188} & \multicolumn{2}{|c|}{0.3220} & \multicolumn{2}{|c|}{0.3221} & \multicolumn{2}{|c|}{0.3069} \\
\hline
\end{tabular}




\section{Table 5 (continued)}

\begin{tabular}{|c|c|c|c|c|c|c|c|c|c|c|}
\hline \multirow{3}{*}{ Variables } & \multicolumn{10}{|c|}{$j$-value } \\
\hline & \multicolumn{2}{|c|}{1} & \multicolumn{2}{|c|}{2} & \multicolumn{2}{|c|}{3} & \multicolumn{2}{|c|}{4} & \multicolumn{2}{|c|}{5} \\
\hline & Coeff. & t-stat. & Coeff. & t-stat. & Coeff. & t-stat. & Coeff. & t-stat. & Coeff. & t-stat. \\
\hline \multicolumn{11}{|c|}{ Options/Futures } \\
\hline Intercept & -411.03 & -0.30 & -1846.47 & -1.33 & -3265.25 & $-2.36 * *$ & -3394.70 & $-2.46 * *$ & -1919.55 & -1.39 \\
\hline$D_{t-j}^{\sigma}$ & 0.004 & 1.42 & -0.00001 & -0.00 & -0.0006 & -0.21 & -0.002 & -0.74 & -0.004 & -1.43 \\
\hline $\operatorname{Adj}-R^{2}$ & \multicolumn{2}{|c|}{0.3535} & \multicolumn{2}{|c|}{0.3386} & \multicolumn{2}{|c|}{0.3399} & \multicolumn{2}{|c|}{0.3423} & \multicolumn{2}{|c|}{0.3401} \\
\hline \multicolumn{11}{|l|}{ Money Spread } \\
\hline Intercept & 1311.80 & 0.93 & -1117.79 & -0.79 & -2362.68 & -1.70 & -2244.53 & -1.60 & -583.75 & -0.42 \\
\hline$D_{t-j}^{\sigma}$ & 0.01 & 0.61 & -0.003 & -0.25 & 0.01 & 0.66 & -0.0001 & -0.01 & 0.01 & 0.76 \\
\hline $\operatorname{Adj}-R^{2}$ & \multicolumn{2}{|c|}{0.3201} & \multicolumn{2}{|c|}{0.3133} & \multicolumn{2}{|c|}{0.3212} & \multicolumn{2}{|c|}{0.3231} & \multicolumn{2}{|c|}{0.3119} \\
\hline \multicolumn{11}{|c|}{ Calendar Spread } \\
\hline Intercept & 687.26 & 0.43 & -1342.72 & -0.85 & -2163.78 & -1.35 & -2144.90 & -1.34 & -292.41 & -0.19 \\
\hline$D_{t-j}^{\sigma}$ & -0.004 & -0.13 & -0.009 & -0.28 & 0.01 & 0.48 & 0.01 & 0.44 & -0.02 & -0.59 \\
\hline $\operatorname{Adj}-R^{2}$ & \multicolumn{2}{|c|}{0.3092} & \multicolumn{2}{|c|}{0.3206} & \multicolumn{2}{|c|}{0.3253} & \multicolumn{2}{|c|}{0.3204} & \multicolumn{2}{|c|}{0.3092} \\
\hline
\end{tabular}




\section{Table 6}

Volatility prediction by the options volume of alternative vanilla trades for different categories of traders. This table reports the estimation results of the prediction regression (Equation 4) on market aggregation and alternative vanilla trading strategies (open or close positions) for various categories of traders. The dependent variable of the regressions is the realized volatility of the TAIEX index on trading day $t$. Of the independent variables, we examine the option-volume variables $\left(D^{\sigma}\right.$, $O P V$ and $A D$ ) with lagged periods from 1 to 5. In order to save space, we do not report the estimates of all of the control variables. The sample period runs from December 2001 to December 2005. * indicates significance at below the $10 \%$ level; ** indicates significance at below the 5\% level; and *** indicates significance at below the $1 \%$ level.

\begin{tabular}{|c|c|c|c|c|c|c|c|c|c|c|}
\hline \multirow{3}{*}{ Variables } & \multicolumn{10}{|c|}{$j$-value } \\
\hline & \multicolumn{2}{|c|}{1} & \multicolumn{2}{|c|}{2} & \multicolumn{2}{|c|}{3} & \multicolumn{2}{|c|}{4} & \multicolumn{2}{|c|}{5} \\
\hline & Coeff. & t-stat. & Coeff. & t-stat. & Coeff. & t-stat. & Coeff. & t-stat. & Coeff. & t-stat. \\
\hline \multicolumn{11}{|c|}{ Panel A: Domestic Institutional Traders } \\
\hline \multicolumn{11}{|c|}{ Overall Volume } \\
\hline Intercept & 1477.30 & 1.08 & -451.35 & -0.33 & -1912.92 & -1.39 & -2162.97 & -1.59 & -649.93 & -0.48 \\
\hline$D_{t-j}^{\sigma}$ & -0.001 & -0.28 & -0.002 & -1.09 & 0.0004 & 0.22 & -0.0001 & -0.08 & 0.0006 & 0.29 \\
\hline $\operatorname{Adj}-R^{2}$ & \multicolumn{2}{|c|}{0.3468} & \multicolumn{2}{|c|}{0.3394} & \multicolumn{2}{|c|}{0.3378} & \multicolumn{2}{|c|}{0.3414} & \multicolumn{2}{|c|}{0.3357} \\
\hline \multicolumn{11}{|l|}{ Open Volume } \\
\hline Intercept & 1390.07 & 1.01 & -719.95 & -0.53 & -1972.13 & -1.43 & -2282.41 & -1.67 & -657.24 & -0.48 \\
\hline$D_{t-j}^{\sigma}$ & 0.001 & 0.57 & -0.0003 & -0.16 & -0.001 & -0.47 & -0.001 & -0.33 & -0.0002 & -0.11 \\
\hline $\operatorname{Adj}-R^{2}$ & \multicolumn{2}{|c|}{0.3506} & \multicolumn{2}{|c|}{0.3448} & \multicolumn{2}{|c|}{0.3388} & \multicolumn{2}{|c|}{0.3411} & \multicolumn{2}{|c|}{0.3355} \\
\hline \multicolumn{11}{|c|}{ Close Volume } \\
\hline Intercept & -107.40 & -0.07 & -2517.31 & -1.61 & -3154.16 & -2.07 & -2577.23 & $-1.69 *$ & -2130.26 & -1.41 \\
\hline$D_{t-j}^{\sigma}$ & 0.003 & 0.70 & 0.0001 & 0.03 & -0.001 & -0.16 & 0.002 & 0.47 & 0.004 & 1.12 \\
\hline $\operatorname{Adj}-R^{2}$ & \multicolumn{2}{|c|}{0.3061} & \multicolumn{2}{|c|}{0.3014} & \multicolumn{2}{|c|}{0.3173} & \multicolumn{2}{|c|}{0.3007} & \multicolumn{2}{|c|}{0.3068} \\
\hline \multicolumn{11}{|c|}{ Panel B: Foreign Institutional Traders } \\
\hline \multicolumn{11}{|c|}{ Overall Volume } \\
\hline Intercept & -12.84 & -0.01 & -2972.15 & $-2.07 * *$ & -3182.75 & $-2.18 * *$ & -2292.35 & -1.56 & -1400.06 & -0.97 \\
\hline$D_{t-j}^{\sigma}$ & 0.0002 & 0.14 & -0.002 & -1.04 & -0.002 & -0.95 & 0.00002 & 0.01 & 0.001 & 0.56 \\
\hline $\operatorname{Adj}-R^{2}$ & \multicolumn{2}{|c|}{0.2999} & \multicolumn{2}{|c|}{0.2992} & \multicolumn{2}{|c|}{0.3021} & \multicolumn{2}{|c|}{0.3107} & \multicolumn{2}{|c|}{0.3081} \\
\hline
\end{tabular}




\section{Table 6 (Continued)}

\begin{tabular}{|c|c|c|c|c|c|c|c|c|c|c|}
\hline \multirow{3}{*}{ Variables } & \multicolumn{10}{|c|}{$j$-value } \\
\hline & \multicolumn{2}{|c|}{1} & \multicolumn{2}{|c|}{2} & \multicolumn{2}{|c|}{3} & \multicolumn{2}{|c|}{4} & \multicolumn{2}{|c|}{5} \\
\hline & Coeff. & t-stat. & Coeff. & t-stat. & Coeff. & t-stat. & Coeff. & t-stat. & Coeff. & t-stat. \\
\hline \multicolumn{11}{|c|}{ Panel B: Foreign Institutional Traders (Contd.) } \\
\hline \multicolumn{11}{|l|}{ Open Volume } \\
\hline Intercept & 1932.60 & 1.40 & -108.35 & -0.08 & -2023.40 & -1.46 & -2193.97 & -1.60 & -736.42 & -0.53 \\
\hline$D_{t-j}^{\sigma}$ & -0.006 & -1.61 & -0.006 & $-1.78 *$ & 0.002 & 0.44 & -0.0003 & -0.07 & 0.001 & 0.16 \\
\hline $\operatorname{Adj}-R^{2}$ & \multicolumn{2}{|c|}{0.3441} & \multicolumn{2}{|c|}{0.3378} & \multicolumn{2}{|c|}{0.3351} & \multicolumn{2}{|c|}{0.3380} & \multicolumn{2}{|c|}{0.3338} \\
\hline \multicolumn{11}{|l|}{ Close Volume } \\
\hline Intercept & 423.62 & 0.30 & -1486.08 & -1.05 & -2799.64 & $-1.98 * *$ & -2772.32 & $-1.97 * *$ & -829.96 & -0.59 \\
\hline$D_{t-j}^{\sigma}$ & 0.001 & 0.88 & 0.0002 & 0.33 & 0.0003 & 0.47 & 0.00003 & 0.06 & -0.00004 & -0.08 \\
\hline $\operatorname{Adj}-R^{2}$ & \multicolumn{2}{|c|}{0.3527} & \multicolumn{2}{|c|}{0.3448} & \multicolumn{2}{|c|}{0.3411} & \multicolumn{2}{|c|}{0.3424} & \multicolumn{2}{|c|}{0.3389} \\
\hline \multicolumn{11}{|c|}{ Panel C: $\quad$ Individual Traders } \\
\hline \multicolumn{11}{|c|}{ Overall Volume } \\
\hline Intercept & 712.26 & 0.52 & -1078.62 & -0.79 & -2398.49 & $-1.76^{*}$ & -2819.37 & $-2.08^{* *}$ & -1241.42 & -0.91 \\
\hline$D_{t-j}^{\sigma}$ & 0.001 & $1.71 *$ & 0.002 & $2.02 * *$ & 0.001 & 0.69 & -0.0003 & -0.45 & 0.001 & 0.82 \\
\hline $\operatorname{Adj}-R^{2}$ & \multicolumn{2}{|c|}{0.3526} & \multicolumn{2}{|c|}{0.3417} & \multicolumn{2}{|c|}{0.3379} & \multicolumn{2}{|c|}{0.3411} & \multicolumn{2}{|c|}{0.3376} \\
\hline \multicolumn{11}{|l|}{ Open Volume } \\
\hline Intercept & 294.58 & 0.20 & -2329.33 & -1.62 & -2602.05 & -1.79 & -2683.69 & -1.83 & -1373.04 & -0.95 \\
\hline$D_{t-j}^{\sigma}$ & 0.00003 & 0.01 & -0.002 & -0.83 & 0.001 & 0.56 & 0.001 & 0.29 & 0.0005 & 0.21 \\
\hline $\operatorname{Adj}-R^{2}$ & \multicolumn{2}{|c|}{0.3024} & \multicolumn{2}{|c|}{0.2980} & \multicolumn{2}{|c|}{0.3069} & 0.3 & & & \\
\hline Close Volume & & & & & & & & & & \\
\hline Intercept & 858.31 & 0.61 & -782.07 & -0.56 & -2463.61 & $-1.76^{*}$ & -2828.95 & $-2.03^{* *}$ & -742.83 & -0.53 \\
\hline$D_{t-j}^{\sigma}$ & 0.001 & $1.75^{*}$ & 0.001 & $2.21 * *$ & 0.0005 & 0.92 & 0.0004 & 0.62 & 0.001 & $2.15^{* *}$ \\
\hline $\operatorname{Adj}-R^{2}$ & & & 0.33 & & 0.3 & & 0.3 & & & \\
\hline
\end{tabular}




\section{Table 7}

Volatility prediction by options volume of alternative combination trades for different categories of traders. This table reports the estimation results of the prediction regression (Equation 4) on alternative volatility sensitive combination trades for various categories of traders. The dependent variable of the regressions is the realized volatility of the TAIEX index on trading day $t$. Of the independent variables, we examine the option-volume variables $\left(D^{\sigma}, O P V\right.$ and $\left.A D\right)$ with lagged periods from 1 to 5 . In order to save space, we do not report the estimates of all of the control variables. The sample period runs from December 2001 to December 2005 . $*$ indicates significance at below the $10 \%$ level; ** indicates significance at below the $5 \%$ level; and *** indicates significance at below the $1 \%$ level.

\begin{tabular}{|c|c|c|c|c|c|c|c|c|c|c|}
\hline \multirow{3}{*}{ Variables } & \multicolumn{10}{|c|}{$j$-value } \\
\hline & \multicolumn{2}{|c|}{1} & \multicolumn{2}{|c|}{2} & \multicolumn{2}{|c|}{3} & \multicolumn{2}{|c|}{4} & \multicolumn{2}{|c|}{5} \\
\hline & Coeff. & t-stat. & Coeff. & t-stat. & Coeff. & t-stat. & Coeff. & t-stat. & Coeff. & t-stat. \\
\hline \multicolumn{11}{|c|}{ Panel A: Domestic Institutional Traders } \\
\hline \multicolumn{11}{|l|}{ Straddle } \\
\hline Intercept & 725.59 & 0.43 & -2459.82 & -1.36 & -3470.91 & $-1.82 *$ & -1697.51 & -0.93 & -696.63 & -0.37 \\
\hline$D_{t-j}^{\sigma}$ & -0.51 & -1.06 & -0.35 & -0.68 & -0.13 & -0.25 & 0.49 & 0.95 & 0.14 & 0.27 \\
\hline $\operatorname{Adj}-R^{2}$ & \multicolumn{2}{|c|}{0.2741} & \multicolumn{2}{|c|}{0.3136} & \multicolumn{2}{|c|}{0.2639} & \multicolumn{2}{|c|}{0.2863} & \multicolumn{2}{|c|}{0.2989} \\
\hline \multicolumn{11}{|l|}{ Strangle } \\
\hline Intercept & 132.74 & 0.08 & -1869.67 & -1.22 & -3066.88 & $-1.98 * *$ & -3212.71 & $-2.09 * *$ & -2031.16 & -1.35 \\
\hline$D_{t-j}^{\sigma}$ & 0.17 & 1.19 & -0.06 & -0.39 & 0.03 & 0.20 & 0.16 & 1.13 & -0.14 & -1.04 \\
\hline $\operatorname{Adj}-R^{2}$ & \multicolumn{2}{|c|}{0.2974} & \multicolumn{2}{|c|}{0.2815} & \multicolumn{2}{|c|}{0.2871} & \multicolumn{2}{|c|}{0.2986} & \multicolumn{2}{|c|}{0.3052} \\
\hline \multicolumn{11}{|c|}{ Options/Futures } \\
\hline Intercept & 1505.98 & 1.10 & -449.09 & -0.33 & -1988.63 & -1.45 & -2290.68 & $-1.68 *$ & -453.41 & -0.33 \\
\hline$D_{t-j}^{\sigma}$ & 0.02 & 0.57 & -0.002 & -0.06 & 0.05 & 1.59 & 0.01 & 0.19 & 0.02 & 0.72 \\
\hline $\operatorname{Adj}-R^{2}$ & \multicolumn{2}{|c|}{0.3384} & \multicolumn{2}{|c|}{0.3307} & \multicolumn{2}{|c|}{0.3324} & \multicolumn{2}{|c|}{0.3332} & \multicolumn{2}{|c|}{0.3277} \\
\hline \multicolumn{11}{|c|}{ Panel B: Foreign Institutional Traders } \\
\hline \multicolumn{11}{|l|}{ Straddle } \\
\hline Intercept & -3256.85 & -0.21 & 32106.00 & 1.78 & -24232.00 & -1.82 & 4391.91 & 0.11 & -2352.09 & -0.19 \\
\hline$D_{t-j}^{\sigma}$ & 0.02 & 0.04 & 0.15 & 0.38 & 0.26 & 1.45 & -0.22 & -0.43 & 0.19 & 1.18 \\
\hline $\operatorname{Adj}-R^{2}$ & \multicolumn{2}{|c|}{0.3534} & \multicolumn{2}{|c|}{0.3644} & \multicolumn{2}{|c|}{0.8219} & \multicolumn{2}{|c|}{0.0659} & \multicolumn{2}{|c|}{0.4664} \\
\hline
\end{tabular}




\section{Table 7 (continued)}

\begin{tabular}{|c|c|c|c|c|c|c|c|c|c|c|}
\hline \multirow{3}{*}{ Variables } & \multicolumn{10}{|c|}{$j$-value } \\
\hline & \multicolumn{2}{|c|}{1} & \multicolumn{2}{|c|}{2} & \multicolumn{2}{|c|}{3} & \multicolumn{2}{|c|}{4} & \multicolumn{2}{|c|}{5} \\
\hline & Coeff. & t-stat. & Coeff. & t-stat. & Coeff. & t-stat. & Coeff. & t-stat. & Coeff. & t-stat. \\
\hline \multicolumn{11}{|c|}{ Panel B: Foreign Institutional Traders (Contd.) } \\
\hline \multicolumn{11}{|l|}{ Strangle } \\
\hline Intercept & 6649.62 & 1.15 & -4920.61 & -0.81 & 7842.38 & 1.55 & 151.64 & 0.02 & -5436.84 & -0.61 \\
\hline$D_{t-j}^{\sigma}$ & 0.14 & 0.98 & 0.01 & 0.06 & -0.07 & -0.57 & -0.12 & -0.55 & 0.38 & $1.79 *$ \\
\hline $\operatorname{Adj}-R^{2}$ & \multicolumn{2}{|c|}{0.4203} & \multicolumn{2}{|c|}{0.3055} & \multicolumn{2}{|c|}{0.5906} & \multicolumn{2}{|c|}{0.2925} & \multicolumn{2}{|c|}{0.5509} \\
\hline \multicolumn{11}{|c|}{ Options/Futures } \\
\hline Intercept & 7361.47 & 1.28 & -9915.96 & $-1.89 *$ & -8107.09 & -1.49 & 2467.69 & 0.53 & 287.67 & 0.05 \\
\hline$D_{t-j}^{\sigma}$ & 0.12 & $3.47 * * *$ & 0.0121 & 0.37 & 0.03 & 0.77 & 0.01 & 0.38 & -0.005 & -0.14 \\
\hline $\operatorname{Adj}-R^{2}$ & \multicolumn{2}{|c|}{0.2989} & \multicolumn{2}{|c|}{0.2989} & \multicolumn{2}{|c|}{0.3288} & \multicolumn{2}{|c|}{0.3654} & \multicolumn{2}{|c|}{0.2005} \\
\hline \multicolumn{11}{|c|}{ Panel C: Individual Traders } \\
\hline \multicolumn{11}{|l|}{ Straddle } \\
\hline Intercept & 290.58 & 0.20 & -1223.93 & -0.85 & -2506.51 & $-1.74 *$ & -2430.50 & $-1.73 *$ & -359.18 & -0.25 \\
\hline$D_{t-j}^{\sigma}$ & 0.05 & 1.25 & 0.04 & 0.93 & 0.01 & 0.25 & 0.03 & 0.78 & 0.004 & 0.09 \\
\hline $\operatorname{Adj}-R^{2}$ & \multicolumn{2}{|c|}{0.3113} & \multicolumn{2}{|c|}{0.3124} & \multicolumn{2}{|c|}{0.3168} & \multicolumn{2}{|c|}{0.3231} & \multicolumn{2}{|c|}{0.3069} \\
\hline \multicolumn{11}{|l|}{ Strangle } \\
\hline Intercept & 947.04 & 0.67 & -2071.67 & -1.44 & -3196.61 & $-2.26 * *$ & -3200.29 & $-2.26 * *$ & -813.63 & -0.57 \\
\hline$D_{t-j}^{\sigma}$ & -0.003 & -0.26 & 0.008 & 0.62 & 0.02 & $1.95^{*}$ & -0.01 & -0.81 & -0.002 & -0.12 \\
\hline $\operatorname{Adj}-R^{2}$ & \multicolumn{2}{|c|}{0.3185} & \multicolumn{2}{|c|}{0.3189} & \multicolumn{2}{|c|}{0.3213} & 0.3 & & & \\
\hline Options/Futu & & & & & & & & & & \\
\hline Intercept & -450.91 & -0.33 & -1906.49 & -1.38 & -3305.17 & $-2.39 * *$ & -3446.64 & $-2.50 * *$ & -1966.93 & -1.42 \\
\hline$D_{t-j}^{\sigma}$ & 0.003 & 0.95 & -0.0003 & -0.08 & -0.001 & -0.44 & -0.003 & -0.80 & -0.005 & -1.44 \\
\hline $\operatorname{Adj}-R^{2}$ & & & 0.3 & & 0.3 & & 0.3 & & & \\
\hline
\end{tabular}

